\title{
Induction of DnaK and GroEL in Brucella Ovis under Various Stress Conditions
}

\author{
Luminita Monica Vanghele ${ }^{1}$, Maria Ionescu ${ }^{1}$, Handan Coste $^{1}$ and Elena Ganea ${ }^{2}$ \\ ${ }^{1}$ Institute for Diagnosis and Animal Health, Bucharest, Romania \\ ${ }^{2}$ Institute of Biochemistry of the Romanian Academy, Bucharest, Romania
}

Correspondence should be addressed to: Luminita Monica Vanghele; vanghele.monica@idah.ro

Received 13 June 2013; Accepted 14 July 2013; Published 29 September 2013

Academic Editor: Krystyna Izabella Wolska

Copyright @ 2013 Luminita Monica Vanghele, Maria Ionescu, Handan Coste and Elena Ganea.

Distributed under Creative Commons CC-BY 3.0

\begin{abstract}
Brucella ovis is a facultative intracellular pathogen, able to survive and replicate within macrophages. The role of molecular chaperones in Brucella intracellular survival has been previously mentioned, but nothing was published on $B$. ovis in this respect, as far as we know. In the present work, in order to understand any possible contribution of the molecular chaperones DnaK and GroEL for Brucella ovis stress survival and intracellular persistance, the expression on different culture media under different stress conditions were analysed at the transcriptional and translational levels and compared with that of bacteria grown inside murine J774A.1 cells. The transcription analyses showed different levels of $d n a K$ and groEL induction under various stress conditions (e.g., macrophages survival, acidic $\mathrm{pH}$ shock, high temperature, oxidative and osmotic shock) and a significant influence of the media composition. These results were consistent with the level of DnaK and GroEL expression analysed by the traditional proteomic methods. Here we demonstrate the molecular chaperones involvement in macrophage- $B$. ovis interaction, their expression under stress conditions suggesting the chaperones role in the bacterial resistance to such unfavourable environmental conditions.
\end{abstract}

Keywords: Gene expression $\cdot$ Brucella ovis $\cdot$ DnaK $\cdot$ GroEL.

\section{Introduction}

Brucella ovis is a facultative intracellular pathogen associated with epididymitis and abortion in sheep, being less studied than the zoonotic species of Brucella, although the infection produced by these bacteria represents an important economical problem in many countries. Survival and multiplication in host phagocytic cells are crucial in the pathogenesis of Brucella infections (Young, 2009; von Bargen et al., 2012). Along with other adaptive mechanisms used by B. ovis (Celli, 2006; Guerra, 2007; Roop et al., 2009), a stress response would presumably increase the chances of pathogen survival and dissemination. The molecular chaperones DnaK (70 kDa) and GroEL (60 kDa) are highly immunogenic or stress proteins induced under various stress conditions in Brucella melitensis, B. abortus and B. suis (Hendrick and Hartl, 1993; Lin and Ficht, 1995a; Köhler et al., 1996; Rafie-Kolpin et al., 1996; Teixeira-Gomes et al., 2000; Kohler et al., 2002). In other bacteria (Escherichia coli, 
Lactobacillus rhamnosus and Caulobacter crescentus), it has been reported by previous papers that GroEL and DnaK are induced during osmotic stress (Meury and Kohiyama, 1991; Bianchi and Baneyx, 1999; Prasad et al., 2003; Susin et al., 2006).

In B. ovis, DnaK and GroEL have been identified as immunogenic proteins (TeixeiraGomes et al., 1997), but the involvement of these proteins in the resistance of $B$. ovis cells in macrophages are not mentioned in the literature, as far as we know.

In this study, the chaperone proteins expression of $B$. ovis grown inside murine J774A.1 cells has been compared with that of bacteria grown in the different cell culture media under various stress conditions, such as acidic $\mathrm{pH}$, high temperature and oxidative stress, which reproduce macrophage intracellular environment. We analyzed also the importance of DnaK and GroEL for B. ovis cells survival in the presence of high concentration of glucose.

A sensitive and powerful technique for quantification of nucleic acids, real time quantitative RT-PCR, was used for the estimation of the transcription of $d n a K$ and groEL genes. In addition, the DnaK and GroEL expression was also analyzed at the translational level by SDS-PAGE and Western blot analysis.

\section{Materials and Methods}

\section{Bacterial Strain and Culture Conditions}

B. ovis 202 was obtained from the Bacteriology Department, IDAH (Institute for Diagnosis and Animal Health), Romania. This strain was confirmed as $B$. ovis by standard biotyping procedures described by Alton et al. (1988). B. ovis cells were grown in an atmosphere containing $5 \% \mathrm{CO}_{2}$ for 72 to $89 \mathrm{~h}$ at $37^{\circ} \mathrm{C}$ in three different culture media: tryptic soy broth (TSB) (Oxoid, Cat. No. CM0129B); brain heart infusion (BHI) broth (Oxoid, Cat. No. CM1135B) and Columbia agar base (Oxoid, Cat. No. CM0331B) with 5\% sterile defibrinated blood. For all the experiments, in parallel with untreated culture (normal conditions), mentioned above, the stress conditions were induced in the three culture media. For the heat shock response, the temperature was raised to $42^{\circ} \mathrm{C}$ (Lin et al., 1992). For the reduced pH (5.5), the protocol described by Rafie-Kolpin et al. (1996) was followed. The oxidative stress was induced by supplementing the medium with $50 \mathrm{mM} \mathrm{H} \mathrm{H}_{2}$ (Teixeira-Gomes et al., 2000). The response to osmotic stress was tested with $B$. ovis cultures in BHI broth by adding $5 \%$ glucose; $B$. ovis grown in TSB in normal conditions was used as positive control.

\section{SDS-PAGE Analysis}

Proteins were extracted with BioRad ReadyPrep Protein Extraction kit. Essentially, the wet cells $(50 \mu \mathrm{l}$ containing $50 \mu \mathrm{g}$ of protein) were mixed with $1 \mathrm{ml}$ of complete 2D Rehydration/Sample Buffer 1, lysed with Greenbeads (Roche), and centrifuged. The supernatant was mixed with sample buffer and incubated for $5 \mathrm{~min}$ at $95^{\circ} \mathrm{C}$. Triplicate of identical protein concentration, as well as Broad Range molecular weight standard (BioRad) were applied on polyacrylamide (PAA) gel. Gels were stained with $0.1 \%$ Coomassie Brilliant Blue R-250, destained by a solution containing methanol, acetic acid and water (4:1:5) and photographed dried.

\section{Western Blotting (Immunoblotting)}

After electrophoresis, proteins were transferred to a PVDF (polyvinylidene diflouride) membrane using Semi-Dry Transfer Cell (BioRad) according to the instructions recommended by the manufacturer. The mouse anti-GroEL monoclonal antibodies, and the mouse antiDnaK monoclonal antibodies were purchased from StressGen Biotechnologies Corporation. Detection of stress proteins was done with Immun-Blot Assay kit (BioRad).

\section{RNA Extraction and Reverse Transcription (RT)}

RNA was stabilized in RNAprotect Bacteria Reagent (Qiagen). Extraction of total RNA from both the bacterial cultures and from the infection mixtures of macrophages and bacteria was performed with the Qiagen RNeasy Mini Protocol. The samples were treated with DNase I solution (RNase-Free 
DNase Set, Qiagen). Residual DNA contamination of the RNA extracts was estimated using $10 \mu \mathrm{l}$ of total RNA samples as templates for $16 \mathrm{~S}$ rRNA gene real Time PCR without previous reverse transcription. The quantity and purity of the total RNA were measured with a BioPhotometer Eppendorf. Complementary DNA (cDNA) was generated from total RNA with M-MLV RT according to the manufacturer's instructions (Promega) using 2,5 $\mu \mathrm{M}$ of each reverse primer and 100 ng total RNA ( $40 \mu$ l final volume).

\section{Primer and Probe Design}

The specific primers and probes for Brucella ovis dnaK (accession no. M95799.1), groEL (accession no. M82975.1) and 16S rRNA gene (accession no. L26168) were designed in this study with Primer3 software v.0.4.0: dnaK-FP 5'gatgccgacatcgaaaagat3'; dnaK-RP 5'tcttcaccttcaagcgaggt3'; dnaK-P 5'FAMaatatggcgacaaggtttcg-TAMRA3'; groEL-FP 5'ccaaggaagtcgaactggaa3'; groEL-RP 5'agctcagccacaacttcgtt3'; groEL-P 5'FAMggcttccaagaccaacgata-TAMRA3'; 16SrRNA-FP 5'cagctcgtgtcgtgagatgt3'; 16SrRNA-RP 5'cagagtgcaatccgaactga3' and 16SrRNA-P 5'FAM-cgtgctacaatggtggtgacTAMRA3'.

\section{Controls for Semi-Quantitative and Quantitative RT-PCR}

B. ovis 202 grown in TSB pH 7.0 was used as positive control. No-template controls were used for in vitro experiments and RNA of uninfected macrophage was isolated as a negative control. 16S rRNA gene (a housekeeping gene) was chosen as internal control for semi-quantitative RT-PCR analysis for normalization of cDNA samples. The dilutions of cDNA from $10^{\circ}$ to $10^{-3}$ were analysed with primers for $16 \mathrm{~S}$ rRNA gene and the cDNA samples were normalized according to quantified of $16 \mathrm{~S}$ rRNA amplicons. For real time quantitative RT-PCR, the $16 \mathrm{~S}$ rRNA gene, the expression of which is relatively constant in bacteria, was used as a reference.

\section{Semi-Quantitative PCR}

Selected genes were amplified from normalized cDNA samples with specific primers $(0.6 \mu \mathrm{M}$ of each primer). The PCR products were analysed on $1.5 \%$ agarose gel and visualized by ethidium bromide staining.

\section{Real-Time Quantitative PCR (qPCR)}

Samples were amplified in a $20 \mu$ reaction mixture containing $0.5 \mu \mathrm{M}$ of each oligonucleotide primer, $0.5 \mu \mathrm{M}$ fluorescent labelled probe for each gene (dnaK, groEL and $16 \mathrm{~S}$ rRNA) and $5 \mu \mathrm{l}$ normalized cDNA. Amplification program (iQ5 Real Time PCR System-BioRad): $3 \mathrm{~min}$ at $95^{\circ} \mathrm{C}$, then 40 cycles of $30 \mathrm{~s}$ at $95^{\circ}, 30 \mathrm{~s}$ at $56^{\circ} \mathrm{C}$ and $30 \mathrm{~s}$ at $72^{\circ} \mathrm{C}$. The final extension was performed for 3 $\min$ at $72^{\circ} \mathrm{C}$. Relative transcriptional level was determined by the method of $2^{-\Delta \Delta_{\mathrm{Ct}}}$ (Livak and Schmittgen, 2001).

\section{Statistics}

Three replicates were used for all experiments. The relative transcription of the genes and the quantification of the proteins were calculated as the mean \pm the standard deviation (S.D.)

\section{Macrophage Infection Assay}

Macrophage cell infection was assayed as described earlier (Buchmeier and Heffron, 1990). B. ovis 202 cells grown on tryptose agar plates for $89 \mathrm{~h}$ were harvested by centrifugation at $13.000 \mathrm{rpm}$. Then, bacteria were opsonized with polyclonal rabbit antiBrucella ovis antibodies for $30 \mathrm{~min}$ at $37^{\circ} \mathrm{C}$ and washed once in PBS. The plates were infected with Brucella ovis at a density of 50 bacteria per macrophage and incubated at $37^{\circ} \mathrm{C}$ in $5 \% \mathrm{CO} 2$ and a humidified atmosphere for $60 \mathrm{~min}$. The cells were then washed three times with PBS to remove extracellular bacteria. The cells were incubated for $1 \mathrm{~h}$ in DMEM/F12 (Dulbecco's Modified Eagle Medium: Nutrient Mixture F-12) (Life Technologies, Cat. No. 11320-074) supplemented with $100 \mu \mathrm{g} / \mathrm{ml}$ ampicillin plus $50 \mu \mathrm{g} / \mathrm{ml}$ kanamycin to kill the extracellular still present bacteria. To ensure that macrophage protein synthesis was inhibited, $50 \mu \mathrm{g} / \mathrm{ml}$ cycloheximide was added to uninfected macrophages. At various time points post infection, the macrophages were lysed with $0,2 \%$ (vol/vol) ice-cold Triton X- 
100 for $30 \mathrm{~min}$ and bacterial cells were collected by centrifugation at $13.000 \mathrm{rpm}$ for $15 \mathrm{~min}$. All the infection experiments were performed in triplicate. Two control wells (positive and negative) were stained by conventional Giemsa method.

\section{Results and Discussion}

Survival and replication of Brucella in host phagocytes are the key components of their virulence (Enright, 1990; Smith and Ficht, 1990). In order to understand any possible contribution of the molecular chaperones DnaK and GroEL for Brucella ovis stress survival and intracellular persistance, the expression in different culture media under different stress conditions were analysed at the transcriptional and translational levels and compared with that of bacteria grown inside murine J774A.1 cells. A proteomic approach was performed by other authors with B. suis, B. abortus and B. melitensis (Lin and Ficht, 1995; Kohler et al., 1996; TeixeiraGomes et al., 2000) and the proteins implicated in intracellular survival were identified. In the proteomic analysis of Brucella melitensis, Teixeira Gomes et al. (2000) found 62 protein spots that showed either increased (DnaK, GroEL, AapJ, RRF, Fe Mn SOD, Cu Zn SOD) or decreased (AlphaETF, ClpP, bacterioferritin, BvrR, IalB, and pyruvate dehydrogenase E1 component beta subunit) levels depending of the stress.

The transcription level of the dnaK and groEL were determined by the combination of semiquantitative RT-PCR and quantitative real time RT-PCR enabled the sensitive quantification of the gene expression. The selected genes were amplified from normalized cDNA samples (Figure 1).

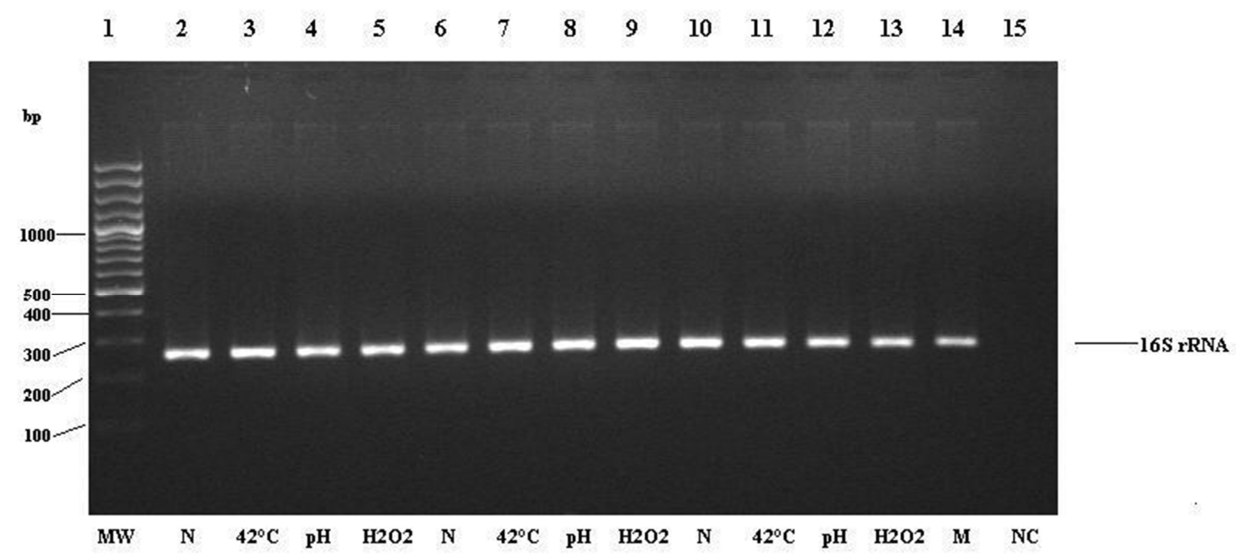

Figure 1: Normalization of the cDNA B. ovis Samples according to Quantity of 16S rRNA Products. Lane 1: 100-3000 bp DNA Ladder (MW); Lanes 2-5 (TSB): Lane 2: Normal Conditions (N), Lane 3: Heat Shock $\left(42^{\circ} \mathrm{C}\right)$, Lane 4: pH $5.5(\mathrm{pH})$, Lane 5: $50 \mathrm{mM} \mathrm{H}_{2} \mathrm{O}_{2}\left(\mathrm{H}_{2} \mathrm{O}_{2}\right)$; Lanes 6-9 (BHI with 5\% Glc): Lane 6: Normal Culture (N), Lane 7: Heat Shock $\left(42^{\circ} \mathrm{C}\right)$, Lane 8:

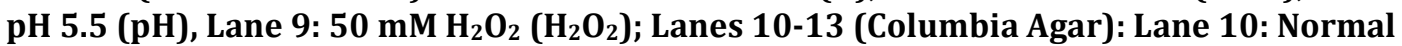
Conditions (N), Lane 11: Heat Shock $\left(42^{\circ} \mathrm{C}\right)$, Lane 12: pH $5.5(\mathrm{pH})$, Lane 13: $50 \mathrm{mM} \mathrm{H}_{2} \mathrm{O}_{2}$ $\left(\mathrm{H}_{2} \mathrm{O}_{2}\right)$; Lane 14: B. ovis Infected Macrophages (M); Lane 15: no-Template Control (NC).

Three replicate were used for each $d n a K$ and groEL real time qRT-PCR experiment and the relative transcription (R) was calculated. The transcription of these two genes was modified under different stress conditions depending on media content (Table 1); the results of Western blot analysis under all the stress conditions used in vitro are a confirmation of this. Real Time RT-PCR showed that DnaK and GroEL were induced during macrophage cell infection (Table 1). 
Table 1: Transcription of dnaK and groEL Measured by Real Time qRT-PCR in B. ovis in Different Stress Conditions: PC (Positive Control): TSB, Normal Conditions; R: Relative Transcription Determinated by the Method of $2^{-\Delta \Delta_{\mathrm{Ct}}}$ (Livak and Schmittgen, 2001) \pm Standard Deviation (S.D.) of Three Replicates.

\begin{tabular}{|c|c|c|c|c|c|c|}
\hline \multirow{3}{*}{ Sample } & \multicolumn{6}{|c|}{ Relative transcription (R) } \\
\hline & \multicolumn{3}{|c|}{ dnaK gene } & \multicolumn{3}{|c|}{ groEL gene } \\
\hline & TSB & $\begin{array}{c}\text { BHI with } \\
5 \% \\
\text { glucose } \\
\end{array}$ & $\begin{array}{c}\text { Columbi } \\
\text { a } \\
\text { agar } \\
\end{array}$ & TSB & $\begin{array}{c}\text { BHI with } \\
5 \% \\
\text { glucose } \\
\end{array}$ & $\begin{array}{c}\text { Columbia } \\
\text { agar }\end{array}$ \\
\hline PC & \multirow[b]{2}{*}{$1 \pm 0.43$} & $1 \pm 1.08$ & $1 \pm 0.31$ & \multirow[b]{2}{*}{$1 \pm 0.12$} & $1 \pm 0.33$ & $1 \pm 0.33$ \\
\hline $\begin{array}{l}\text { normal } \\
\text { conditions } \\
(\mathrm{N})\end{array}$ & & $5.31 \pm 0.9$ & $1.16 \pm 0.41$ & & $9.25 \pm 0.44$ & $7.78 \pm 1.06$ \\
\hline heat $\left(42^{\circ} \mathrm{C}\right)$ & $18.5 \pm 0.06$ & $49.18 \pm 0.63$ & $1.3 \pm 0.97$ & $14.92 \pm 0.09$ & $22.78 \pm 0.3$ & $35.26 \pm 0.16$ \\
\hline $\mathrm{H}_{2} \mathrm{O}_{2}$ & $0.76 \pm 0.65$ & $21.7 \pm 0.07$ & $1.12 \pm 0.46$ & $1.27 \pm 0.32$ & $22.47 \pm 0.33$ & $18.76 \pm 0.41$ \\
\hline low pH & $18.24 \pm 0.10$ & $340 \pm 0.81$ & $1.40 \pm 0.96$ & $17.87 \pm 0.04$ & $\begin{array}{c}103.96 \pm 0.2 \\
3 \\
\end{array}$ & $37.27 \pm 0.68$ \\
\hline Macrophages & \multicolumn{3}{|c|}{$27.28 \pm 0.59$} & \multicolumn{3}{|c|}{$29.24 \pm 0.66$} \\
\hline
\end{tabular}

The results of the real time quantitative PCR of dnaK and groEL genes were consistent with the observation that the induction of DnaK and GroEL depends on the transcription (Cardoso et al., 2010). The semi-quantitative PCR of the genes has been a less sensitive method that showed the different levels of the transcription, being a partial confirmation of the other two methods results (Figure 2).

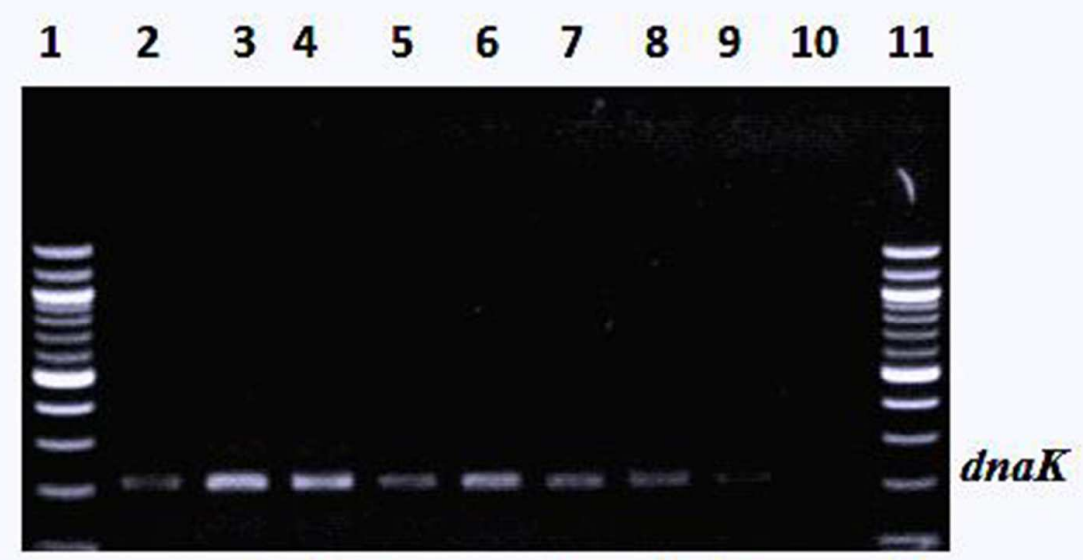

$\begin{array}{lllllllllllll}M & \mathrm{~N} & 42^{\circ} \mathrm{C} & \mathrm{pH} & \mathrm{H}_{2} \mathrm{O}_{2} & \mathrm{~N} & 42^{\circ} \mathrm{C} & \mathrm{pH} & \mathrm{H}_{2} \mathrm{O}_{2} \mathrm{NC} & \mathrm{M}\end{array}$

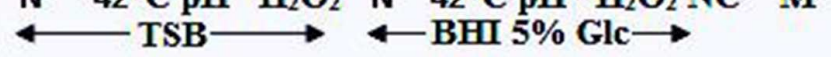

Figure 2: Relative Transcription of dnaK Gene in B. ovis Grown in TSB and BHI with $5 \%$ Glucose by semi-Quantitative RT-PCR. Lane 1 and 11: DNA Molecular Weight Standard Marker (M); Lanes 2-5 (TSB): Lane 2: Normal Conditions (N), Lane 3: Heat Shock $\left(42^{\circ} \mathrm{C}\right)$, Lane 4: pH $5.5(\mathrm{pH})$, Lane 5: $50 \mathrm{mM} \mathrm{H}_{2} \mathrm{O}_{2}\left(\mathrm{H}_{2} \mathrm{O}_{2}\right)$; Lanes 6-9 (BHI with 5\% Glc): Lane 6: Normal

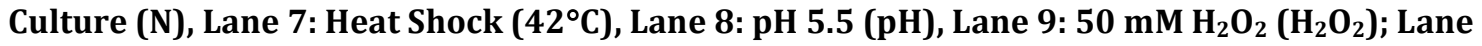
10: Negative Control (NC).

The quantification of the bands intensity for DnaK and GroEL proteins (Figure 3) and the determination of the apparent molecular weight from Western blots were done with UN-SCAN-IT gel ${ }^{\mathrm{TM}}$ software. 


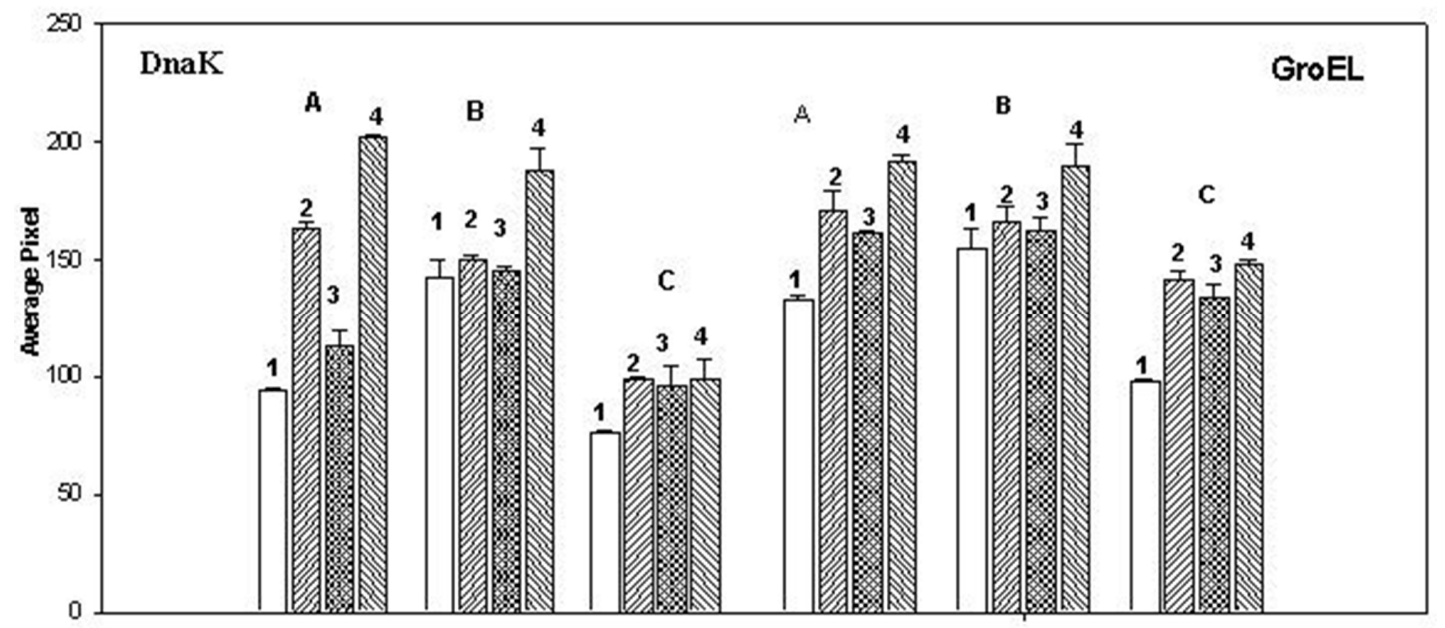

Figure 3: DnaK and GroEL Proteins Quantification by Densitometric Scanning of Western Blot (Average Pixel). A: TSB; B: BHI with 5\% Glucose; C: Columbia Agar. The Stress Conditions Induced in Media: (1) None, (2) Heat Shock $\left(42^{\circ} \mathrm{C}\right)$, (3) $50 \mathrm{mM} \mathrm{H}_{2} \mathrm{O}_{2}$ and (4) pH 5.5, Respectively. The Data Presented are Calculated as the Mean \pm the Standard Deviation (S.D.).

The DnaK and GroEL proteins were identified by the Western blot analysis where the proteins with the same molecular mass as DnaK and GroEL cross-reacted with the antibodies specific for these proteins with the strong reactions. These protein spots were accepted as the DnaK (Figure 4) and GroEL (Figure 5).

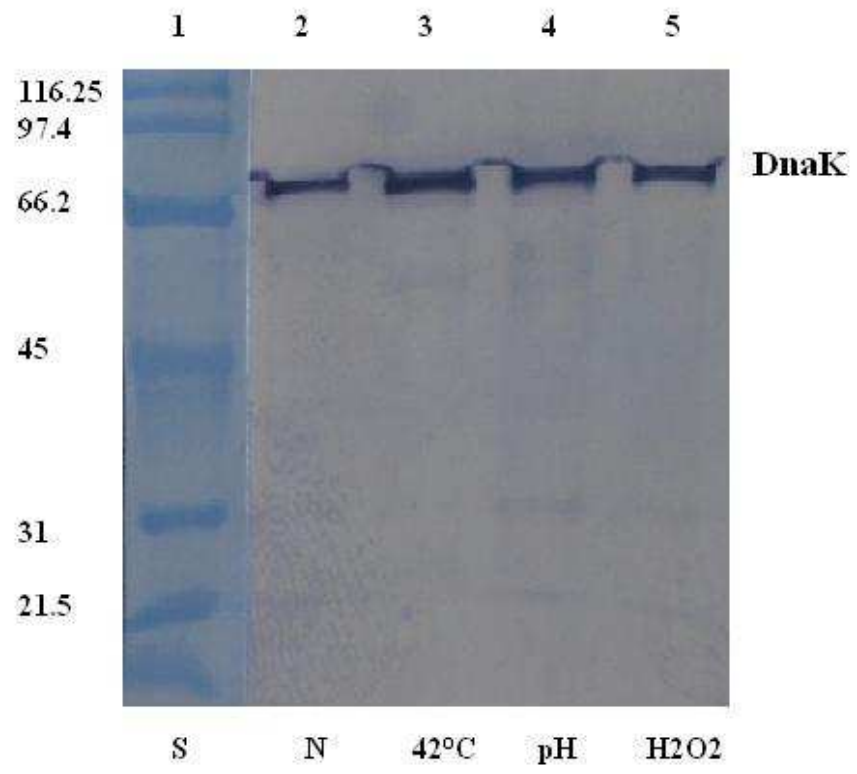

Figure 4: Western Blot Analysis of DnaK Expression in B. ovis Cells Grown in TSB. Lane 1: SDSPAGE Molecular Weight Standard (kDa) (S); Lane 2: Normal Conditions (N); Lane 3: Heat Shock $\left(42^{\circ} \mathrm{C}\right)$; Lane 4: pH $5.5(\mathrm{pH})$; Lane 5: $50 \mathrm{mM} \mathrm{H}_{2} \mathrm{O}_{2}\left(\mathrm{H}_{2} \mathrm{O}_{2}\right)$. 


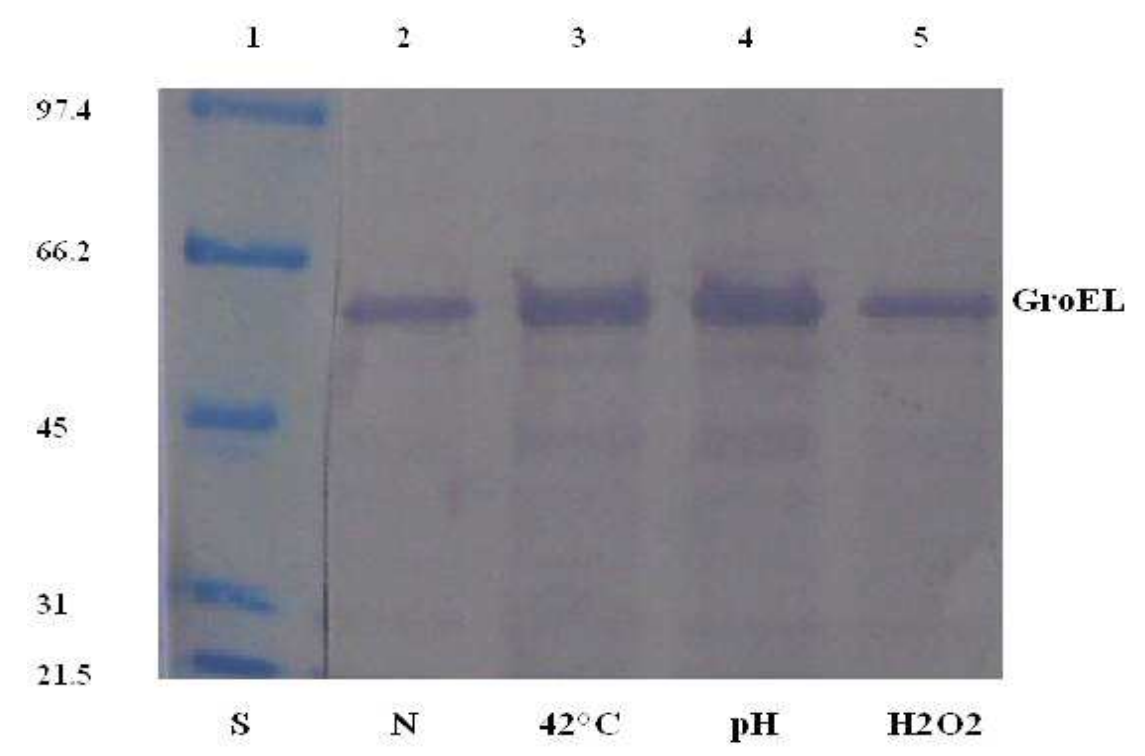

Figure 5: Western Blot Analysis of GroEL Expression in B. ovis Cells Grown in TSB. Lane 1:
SDS-PAGE Molecular Weight Standard (kDa) (S); Lane 2: Normal Conditions (N); Lane 3: Heat
Shock $\left(42^{\circ} \mathrm{C}\right)$; Lane 4: pH $5.5(\mathrm{pH})$; Lane 5: $50 \mathrm{mM} \mathrm{H}_{2} \mathrm{O}_{2}\left(\mathrm{H}_{2} \mathrm{O}_{2}\right)$.

The results showed an increase of protein level corresponding to DnaK in TSB medium, as a response of $B$. ovis to the heat (Figure $3 \mathrm{~A})$. In addition, the DnaK level was increased in BHI medium with $5 \%$ glucose after exposure to the increased temperature (Figure 3B). In contrast, the DnaK expression of $B$. ovis on solid medium with peptone (Columbia agar) was unchanged (Figure 3C). The increased induction of groEL gene by heat shock was observed regardless of the media composition. The effect of the reduced $\mathrm{pH}$ on the chaperone synthesis was estimated by the level of DnaK and GroEL proteins extracted from $B$. ovis cells grown in the TSB, BHI with $5 \%$ glucose and Columbia agar, respectively, at pH 5.5 compared with the same media at pH 7.0 (Figure 3). A major increase in the level of these two molecular chaperones was observed at acid-stressed organisms cultured in TSB (Figure 3A) and BHI with $5 \%$ glucose (Figure 3B). The presence of peptone in the solid medium in the absence of glucose (Columbia agar) caused no change in the DnaK expression as comparing with normal $\mathrm{pH}$ (7.0). Under the same conditions, the level of GroEL expression was increased (Figure 3C).

SDS-PAGE profiles and Western blot analysis of proteins synthesized in $B$. ovis incubated in
TSB medium (Figure 3A) and Columbia agar (Figure 3C) under oxidative conditions show no change in the synthesis of DnaK protein. The high concentration of glucose in medium induced a decrease in DnaK protein synthesis in B. ovis exposed to $50 \mathrm{mM} \mathrm{H}_{2} \mathrm{O}_{2}$ (Figure 3B). The GroEL expression under oxidative conditions was influenced by the media composition. The high concentration of glucose in medium induced an increase in the GroEL protein synthesis under oxidative conditions (Figure 3B) and a small increase of this molecular chaperone level was noticed in the absence of glucose in the solid medium with peptone (Figure 3C). In contrast, the level of GroEL protein was decreased in TSB medium with $50 \mathrm{mM} \mathrm{H}_{2} \mathrm{O}_{2}$ (Figure $3 \mathrm{~A}$ ).

GroEL protein is up-regulated when B. ovis cultures were grown on media with peptone regardless of glucose under all stress conditions. It seems that too much peptone (relative to glucose) present in the medium increases the $\mathrm{pH}$ by the overproduction of ammonium stimulating only the GroEL expression. Under the similar alkaline conditions, the DnaK expression was unchanged, suggesting the response may be shifted by the medium. 
Our results showed a poor correlation between the relative levels of trancription for dnaK (Figure 2) with real time quantitative PCR values (Table 1) in B. ovis cells grown in TSB and BHI media under various stress conditions. It seems that dnaK transcript level (and also groEL) is higher in the BHI broth with $5 \%$ glucose as compared to TSB. This certainly indicates a significant effect of this BHI medium in the induction of the expression of chaperone genes under acidic $\mathrm{pH}$ and heat shock in $B$. ovis, but less against oxidative conditions. This could reflect the increased osmolarity of this medium due to extra glucose supplementation, a stressor promoting this effect in other bacteria, as mentioned above.

B. ovis is a fastidious organism with a low growth and metabolic activity (Tsolis et al., 2009; Al Dahouk et al., 2010). Meyer (1969) showed that $B$. ovis is defective in oxidative metabolism of glucose and other sugars, this finding being confirmed by the recent studies that show the inability of $B$. ovis to use glucose as a primary carbon source, suggesting a correlation between this metabolic deficiency and the narrowing of the tissue tropism and host range of $B$. ovis (Tsolis et al., 2009; Al Dahouk et al 2010). However, McAlpin and Slanetz (1928) showed that all species of Brucella except $B$. abortus are able partly to use the available glucose in the medium, the degree of acid production varied with the different strains (Zobell and Meyer, 1930). In this context, the high levels of dnaK and groEL transcripts in BHI medium with $5 \%$ glucose could be explain by the acidification of the medium, probably by the use of glucose in the fermentation process. As a consequence, these two proteins in $B$. ovis might be involved in the adaptive acid tolerance response.

In this study, using various media for B. ovis culture under stress conditions we have shown that the $B$. ovis stress response was significantly influenced by the media composition._dnaK and groEL transcript levels are higher under reduced $\mathrm{pH}$ and heat shock in rich medium (BHI broth with 5\% glucose) than in minimal medium (TSB); similar data were reported by Lin et al. (1995b) and Foster et al. (1991) regarding the response other pathogenes to the acidic stress.

The comparison of the DnaK and GroEL expression in B. ovis cultures exposed to various environmental stress conditions allowed us to distinguish different levels of these two molecular chaperones expression. The present study revealed that environmental stress rapidly modified the DnaK and GroEL expression in B. ovis. The relative transcription level of the dnaK and groEL genes change under in vitro stress conditions examined, also during macrophage infection. Our results demonstrate that heat, the acid $\mathrm{pH}$ and intramacrophagic cell infection induce the expression of DnaK and GroEL in B. ovis, confirming the previously described data on other Brucella species involved in human pathology, as mentioned above. The $\mathrm{pH}$ reductions are mainly responsible for the induction of these genes inside phagocytic cells providing that the temperature is not changes. dnaK and groEL genes may play possibly an important role in the resistance against the bactericidal activity of macrophages and against the pathogenicity of B. ovis.

The expression of molecular chaperones genes in bacteria is controlled at transcriptional level by both positive and negative mechanisms. In Escherichia coli, the induction of the majority of up-regulated cytoplasmic heat shock proteins occurs through the sigma factor $\left(\sigma^{32}\right)$ located upstream of heat-shock genes (Chuang et al., 1993). The identification of putative heatshock promotor -35 and -10 consensus sequence for $B$. melitensis, $B$ abortus and $B$. ovis suggest that $\sigma^{32}$ could be responsible for the increased cellular levels of DnaK and GroEL expression in Brucella (Cellier et al., 1992; Lin et al., 1992; Teixeira-Gomes et al., 2000). Delory et al. (2006) identified a RpoHlike sigma factor of the RNA polymerase $\left(\sigma^{\mathrm{H} 2}\right)$ with multiple roles in the adaptation of $B$. melitensis to heat, cold and oxidative stress by the control of dnaKJ and groESL operons. These findings could be the potential explanations for the increased cellular levels of DnaK and GroEL in B. ovis inside macrophages and under various stress conditions. 
In addition, the negative heat shock regulation appears to be more prominent in bacteria than positive regulation by $\sigma$ factors. The identification of any putative CIRCE element upstream of the groES operon, but not upstream the dnaKJ operon (Narberhaus, 1999) could explain the differential regulation observed between these two operons in B. ovis.

This study suggests that the molecular chaperones, DnaK and GroEL, are regulated at the transcriptional and translational levels by various stress conditions and that this regulation may help improving the resistance of $B$. ovis cells to environmental stress, including the macrophage microbicidal mechanisms. Our data represent the first transcription analysis of the molecular chaperones in a non-zoonotic Brucella species, regarding the resistance of $B$. ovis cells in macrophages and to various environmental conditions.

\section{References}

Al Dahouk, S., Scholz, H. C., Tomaso, H., Bahn, P., Göllner, C., Karges, W., Appel, B., Hensel, A., Neubauer, H. \& Nöckler, K. (2010). "Differential Phenotyping of Brucella Species Using a Newly Developed Semi-Automated Metabolic System," BMC Microbiology, 10, 269.

Alton, G. G., Jones, L. M., Angus, R. D. \& Verger, J. M. (1988). Techniques for the Brucellosis Laboratory, Paris, Institut National de la Recherche Agronomique.

Bianchi, A. A. \& Baneyx, F. (1999). "Hyperosmotic Shock Induces the $\sigma^{32}$ and $\sigma^{\mathrm{E}}$ Stress Regulons of Escherichia Coli," Molecular Microbiology, 34(5), 1029-1038.

Buchmeier, N. A., \& Heffron, F. (1990). "Induction of Salmonella Stress Proteins upon Infection of Macrophages," Science, 248(4956), 730-732.

Cardoso, K., Gandra, R. F., Wisniewski, E. S., Osaku, C. A., Kadowaki, M. K., Felipach-Neto, V., Haus, L. F., \& Simão, R. de C. (2010). "DnaK and GroEL are Induced in Response to Antibiotic and Heat Shock in Acinetobacter
Baumannii," Journal of Medical Microbiology, 59(P† 9), 1061-1068.

Cellier, M. F., Teyssier, J., Nicolas, M., Liautard, J. P., Marti, J. \& Sri Widada, J. (1992). “Cloning and Characterization of the Brucella Ovis Heat Shock Protein DnaK Functionally Expressed in Escherichia Coli," Journal of Bacteriology, 174, 8036-8042.

Celli, J. (2006). "Surviving inside a Macrophage: The Many Ways of Brucella," Research Microbiology, 157, 93-98.

Chuang, S. E. \& Blattner, F. R. (1993). "Characterization of Twenty-Six New Heat Shock Genes of Escherichia Coli," Journal of Bacteriology, 175(16), 5242-5252.

Enright, F. M. (1990). 'The Pathogenesis and Pathobiology of Brucella Infection in Domestic Animals,' In Animal Brucellosis, Eds. Nielsen, K. and Duncan, J. R. CRC Press, Inc., Boca Raton, Fla., PP. 301-320.

Foster, J. W. (1991). "Salmonella Acid Shock Proteins are Required for the Adaptive Acid Tolerance Response," Journal of Bacteriology, 173(21), 6896-6902.

Guerra, H. (2007). "The Brucellae and their Success as Pathogens," Critical Reviews in Microbiology, 33, 325-331.

Hendrick, J. P. \& Hartl, F.- U. (1993). "Molecular Chaperone Functions of HeatShock Proteins," Annual Review of Biochemistry, 62, 349-384.

Köhler, S., Ekaza, E., Paquet, J.- Y., Walravens, K., Teyssier, J., Godfroid, J. \& Liautard, J.- P. (2002). "Induction of dnaK through its Native Heat Shock Promotor is Necessary for Intramacrophagic Replication of Brucella Suis," Infection and Immunity, 70(3), 16311634.

Köhler, S., Porte, F., Jubier-Maurin, V., Ouahrani-Bettache, S., Teyssier, J. \& Liautard, J. P. (2002). "The Intramacrophagic Environment of Brucella Suis and Bacterial Response," Veterinary Microbiology, 90(1-4) 299-309. 
Köhler, S., Teyssier, J., Cloeckaert, A., Rouot, B. \& Liautard, J. P. (1996). "Participation of the Molecular Chaperone DnaK Intracellular Growth of Brucella Suis within U937-Derived Phagocytes," Molecular Microbiology, 20(4), 701-712.

Lin , J., Adams L. G. \& Ficht T. A. (1992). "Characterization of the Heat Shock Response in Brucella Abortus and Isolation of the Genes Encoding the GroEL Heat Shock Proteins," Infection and Immunity, 60(6), 2425-2431.

Lin, J. \& Ficht, T. A. (1995a). "Protein Synthesis in Brucella Abortus Induced during Macrophage Infection," Infection and Immunity, 63(4), 1409-1414.

Lin, J., Lee, I. S., Frey, J., Slonczewski, J. L. \& Foster, J. W. (1995b). "Comparative Analysis of Extreme Acid Survival in Salmonella Typhimurium, Shigella Flexneri, and Escherichia Coli," Journal of Bacteriology, 177(14), 4097-4104.

McAlpin, J. G. \& Slanetz, C. A. (1928). "Studies on the Metabolism of Abortusmelitensis Group 3. Glucose Utilization," Journal of Infectious Diseases, 42(1), 73-78.

Meury, J. \& Kohiyama, M. (1991). "Role of Heat Shock Protein DnaK in Osmotic Adaptation of Escherichia Coli," Journal of Bacteriology, 173(14), 4404-4410.

Meyer, M. E. (1969). "Brucella Organisms Isolated from Dogs: Comparison of Characteristics of Members of the Genus Brucella," American Journal of Veterinary Research, 30, 1751-1756.

Prasad, J., McJarrow, P. \& Gopal, P. (2003). "Heat and Osmotic Stress Responses of Probiotic Lactobacillus Rhamnosus HN001 (DR20) in Relation to Viability after Drying," Applied Environmental Microbiology, 69(2), 917-925.

Rafie-Kolpin, M., Essenberg, R. C. \& Wyckoff III, J. H. (1996). "Identification and Comparison of Macrophage-Induced Proteins and Proteins Induced under Various Stress Conditions in Brucella Abortus," Infection and Immunity, 64(12), 5274-5283.
Roop, R. M. 2nd, Gaines, J. M., Anderson, E. S., Caswell, C. C. \& Martin, D. W. (2009). "Survival of the Fittest: How Brucella Strains Adapt to their Intracellular Niche in the Host," Medical Microbiology and Immunology, 198(4), 221-238.

Salisbury, S. (1997). 'Genotypic Detection of Methicillin-Resistant Staphylococci by Multiplex PCR Assay,' LabMedica International, 16-7.

Smith, III, R. (1990). 'T lymphocyte-Mediated Mechanisms of Acquired Protective Immunity against Brucellosis in Cattle,' In Advances in brucellosis research, Eds. C Adams, L. G. College Station: Texas A\&M University Press, PP. 164-190.

Susin, M. F., Baldini, R. L., Gueiros-Filho, F. \& Gomes, S. L. (2006). "GroES/GroEL and DnaK/DnaJ Have Distinct Roles in Stress Responses and during Cell Cycle Progression in Caulobacter Crescentus," Journal of Bacteriology, 188(23), 8044-8053.

Teixeira-Gomes, A. P., Cloeckaert, A., Bezard, G., Bowden, R. A., Dubray, G. \& Zygmunt, M. S. (1997). "Identification and Characterization of Brucella Ovis Immunogenic Proteins Using Two-Dimensional Electrophoresis and Immunoblotting," Electrophoresis, 18, 14911497.

Teixeira-Gomes, A. P., Cloeckaert, A. \& Zygmunt, M. S. (2000). "Characterization of Heat, Oxidative, and Acidic Stress Responses in Brucella Melitensis," Infection and Immunity, 68(5), 2954-2961.

Tsolis, R. M., Seshadri, R., Santos, R. L., Sangari, F. J., Lobo, J. M., de Jong, M. F., Ren, Q., Myers, G., Brinkac, L. M., Nelson, W. C., Deboy, R. T., Angiuoli, S., Khouri, H., Dimitrov, G., Robinson, J. R., Mulligan, S., Walker, R. L., Elzer, P. E., Hassan, K. A. \& Paulsen, I. T. (2009). "Genome Degradation in Brucella Ovis Corresponds with Narrowing of its Host Range and Tissue Tropism," PloS ONE, 4(5): e5519. 
von Bargen, K., Gorvel, J. P. \& Salcedo, S. P. (2012). "Internal Affairs: Investigating the Brucella Intracellular Lifestyle," FEMS Microbiology Reviews, 36, 533-562.

Young, E. J. (2009). 'Brucellosis. In Mandell, Douglas and Bennett's Principles and Practice of Infectious Disease,' 7th edn., Eds. Mandell, G.L., Bennett, J.E., and Dolin, R., Churchill Livingstone.

Yushan, H., Lei, L., Weijia., L. \& Xiaoguang, C. (2010). "Sequence Analysis of the groEL Gene and its Potential Application in Identification of Pathogenic Bacteria," African Journal of Microbiology Research, 4(16), 1733-1741.

Zobell, C. E. \& Meyer, K. F. (1930). "Metabolism Studies on the Brucella Group II. The Fermentation of Monosaccharides," Experimental Biology and Medicine, 28(2), 160-162. 